\title{
Trends and Patterns in Fertilizer Consumption: A Case Study
}

\author{
Yudhishther Singh Bagal $^{1 *}$, L.K. Sharma ${ }^{1}$, Gunjan Preet Kaur ${ }^{2}$, \\ Arjun Singh ${ }^{2}$ and Priya Gupta ${ }^{2}$ \\ ${ }^{1}$ Division of Agricultural Extension Education, SKUAST-Jammu, India \\ ${ }^{2}$ Faculty of Agriculture, SKUAST- Jammu, India \\ *Corresponding author
}

\section{A B S T R A C T}

\section{Keywords}

Fertilizer, Buying preference, Brand, Form of fertilizer

\section{Article Info}

Accepted:

07 March 2018

Available Online:

10 April 2018
In this study, an in-depth analysis is done with reference to the consumption pattern of fertilizer at Kotli village of R.S. Pura District in the state of Jammu and Kashmir. A total of 79 farmers were randomly without replacement selected and were interviewed with the help of well-structured interview schedule. The findings revealed that majority of the farmers had marginal ( $<1 \mathrm{ha}$ ) land holding and majority of the respondents apply inorganic fertilizers. Majority of the farmers used fertilizers in the granulated form. The quantity of urea, diammonium phosphate and muriate of potash in rice and wheat were applied in more quantity than recommended. Very few farmers gave preference to nutrient composition, brand and price while purchasing fertilizers. Only those farmers which are more educated gave preference to nutrient composition while purchasing fertilizers.

\section{Introduction}

Agriculture occupies most important role in Indian society and its economy as well. Since Independence, India's food grain production has registered an over a five-fold increase, to around 273 million tonnes in 2016-17 (Kulkarni, 2017). The development of agricultural sector is felt important in India which has to feed billions of people, at least three times a day. Agriculture in India is the means of livelihood of almost two thirds of the work force in the country. During 1950s declining agriculture growth in India compelled to embark upon many development strategies to improve agriculture growth. The country has largely attained self-sufficiency as it transformed itself from a status of importers to an exporter over the past 70 years. The adoption of Green Revolution in the 1960s gave a major impetus to food grain production in the country, which then had largely depended on imports to feed the demand. In achieving targeted food production, introduction of the new agricultural strategy, which propagate the use of critical inputs like high yielding variety; fertilizers, manures etc. Further experiences shows that increased use of fertilizers in a proper proportion increases agricultural productivity and production. Thus, the use of chemical fertilizers has become an integral part of the Indian agriculture from the view point of improving yield. the annual consumption of fertilizers, in nutrient terms 
(N, P \& K), has increased from 0.07 million MT in 1951- 52 to more than 25.95 million MT in 2016- 17 and per hectare consumption, has increased from less than $1 \mathrm{Kg}$ in 1951- 52 to the level of $130.8 \mathrm{Kg}$ now. (FPC 2016-17). Fertilizers are used almost by all the farmers. India is the second largest consumer of fertilizers in the world after China, consuming about 26.5 million tonnes (Sharma and Thaker, 2011). It accounted for 15.3 per cent of the world's $\mathrm{N}$ consumption, 19 per cent of phosphatic (P) and 14.4 percent of potassic (K) nutrients in 2008 (GOI, 2010).

The use of fertilizers is affected by a number of factors like irrigation, high yielding variety seeds, size of the farm credit etc. Increased area under high yielding varieties led to increased food grains production. The high yielding varieties respond more to the use of chemical fertilizers. The main nutrients which must be added to the soil in the form of fertilizers are Nitrogen, Phosphorus and Potassium. Sometimes micro-nutrients such as calcium, magnesium, manganese, boron, etc. would also be required. The present level of three nutrient components that is nitrogen, potassium and phosphate seems to be not fully balanced. The imbalance is due to problems such as all the Nitrogen is being used and lower use of Phosphates and Potash by the soil. Many states are taking measures to correct the imbalances. Thus to check the status of fertilizer consumption in $\mathrm{J} \& \mathrm{~K}$ this study entitled "Trends and Patterns in Fertilizer Consumption: A case study" was conducted.

\section{Materials and Methods}

This study was conducted by PG and UG students of the Sher-e- Kashmir University of Agricultural Sciences and Technology of Jammu. Kotli village of R.S. Pura Tehsil was purposively selected as it was nearer to the university. A list of farming families was prepared with the help of Sarpanch and prominent persons of the village. From the prepared list a total of 79 farming families were randomly selected as respondents. A well structure interview schedule was prepared with the help of experts. The interview was conducted in local dialect i.e., Dogri. Data was collected from October to December, 2017. The respondents were interviewed either at their home, at community places or their farms and responses were recorded on the spot. The interview schedule was pre- tested to find out the ambiguity and weakness in the items of the schedule. The data collected from the respondents were scored, tabulated and analyzed by using computer based SPSS (Statistical Package for Social Sciences).

\section{Results and Discussion}

The data in the Table 1 revealed that, the average age of the respondents was 56.88 years $( \pm 10.31)$. The results further revealed that 68percent of the respondents were in the age group of 46- 67 years. Whereas 16 percent and 15 percent were in the age group of 67-87 years and 34- 45 years respectively. With regard to education of the head of the family, 34 percent of the respondents studied upto 'matriculation' level, 24 percent had education upto 'middle' level and 10 percent studied upto ' $10+2$ ' level. An equal percent ( $4 \%$ ) of the respondents had studied upto 'primary' and graduation and above. About one- fourth of the respondent $(24 \%)$ was illiterate. The probable reason to be illiterate might be the illiteracy of their parents, non-realization of importance of formal education, lack of proper educational facility. The similar situation was also noticed in the findings of Kapoor (2011) and Ali (2011). The average number of formal schooling years completed was 7.45 years $( \pm 4.5)$. The average experience of the respondents in farming and cultivation of crops was 30 years $( \pm 12)$. The reasons may be 
that respondents were agricultural back ground and living in villages. In a farm family, the children right from childhood helps their parents in farm activities and gradually practices it on regular basis. With regard to family size, the average number of family members of the respondents was $4( \pm 1.5)$.

With regard to distance, of the respondents village from different places of agricultural importance, the average distance of the respondents home from the seed, pesticide and fertilizer retailer was 3.4 kilometres, the average distance of respondent home from the nearby market was 3.3 kilometres, the average distance of respondent home from the nearby Department of Agriculture was 5 kilometres and the average distance of respondent home from the nearby Agricultural University was 7 kilometres.

The average annual family income, of the respondent's household was Rs 141243.6 ( \pm 190798.5$) .61$ percent of the households has annual income level of Rs ' 100000 to 96058 , 28 percent and 11 percent had income level of Rs 96058 to 390252 and Rs 390252 to 1000000.40 percent of the respondents were doing farming solely whereas 48 percent, were doing government service in addition to farming An equal percent $(6 \%)$ of the respondents doing trading and other business in addition to farming.

With regards to social participation, only 10 per cent of the respondents were members of village panchayat and only one percent was members of other societies. The reason for low social participation of the respondents in the study area might be due to their busy schedule in agriculture and other subsidiary occupations throughout the year. Another possible reason may be due lack of such organizations and even if they are not present. Their inefficiencies could not motivate the respondents to be their members (Table 2).
Data presented in Table 3 revealed that overall average operational land holding was 0.76 hectares with an average irrigated area of 0.76 hectares, and average unirrigated area of 0.01 hectares. Majority (76\%) of the households fall under the marginal farm size category having less than one ha of land, about 16 percent respondents were in small farm size category having one to two ha of land. An equal percent $(4 \%)$ of the households were fall under the categories of 'semi medium' (2-4 ha) and 'medium' (4-10 ha). None of the household were fall under large category $(>10$ ha) of landholding. With regards to fragmentation of land holding, almost all the respondents $(99 \%)$ were having fragmented land holding with an average number of fragments of $4.4 \pm 3.3$.

With regards to type of fertilizer used Table 4 revealed that 53 percent of the respondents were used both organic and inorganic fertilizers and 47 percent used only inorganic fertilizer. Whereas none of the respondent had used only organic fertilizers.

With regards to kind of fertilizer used, granulated were used by all the respondents, two percent used tablets while one percent used fertilizers in powder and other forms. In case of application of fertilizer, 91 percent of the respondents applied fertilizers by self, 3 percent of the respondents apply fertilizers by labour and 6 percent apply own as well as by labour also. With regards to preference on the basis of quantity while purchasing fertilizers, in case of urea, 51 percent give preference to buy loose, 46 percent to $50 \mathrm{~kg}$ packing and 3 percent give preference to $25 \mathrm{~kg}$ packing. In case of buying DAP, 50 percent give preference to loose quantity, 46 percent to 50 $\mathrm{kg}$ packing while 4 percent to $25 \mathrm{~kg}$ packing. In case of MOP, majority (83\%) give preference to loose quantity and rest 17 percent give preference to $50 \mathrm{~kg}$ packing (Table 5). 
Table.1 Descriptive statistics regarding socio-economic status of the farmer

\begin{tabular}{|c|c|}
\hline Parameter & Total $(n=79)$ \\
\hline Mean age (\% farmers) & $56.88 \pm 10.31$ \\
\hline Young ( 34 to 45 years) & 16 \\
\hline Middle age (46-67 years) & 68 \\
\hline Old age (67-87 years) & 15 \\
\hline Mean education (years) & $7.45 \pm 4.5$ \\
\hline Education level (\% farmers) & \\
\hline i) Illiterate & 24 \\
\hline Below primary & 0 \\
\hline iii) Primary & 4 \\
\hline iv) Middle & 24 \\
\hline Matriculate & 34 \\
\hline vi) $\quad 10+2$ & 10 \\
\hline Graduate and above & 4 \\
\hline Average farming experience (years) & $30 \pm 12$ \\
\hline A verage family size & $4 \pm 1.5$ \\
\hline Average distance of village from $(\mathrm{km})$ & \\
\hline Nearest market & 3.3 \\
\hline ii) Fertilizer retailer & 3.4 \\
\hline Input dealer & 3.5 \\
\hline iv) Department of Agriculture & 5 \\
\hline v) Agricultural University & 7 \\
\hline Average Annual Family income (Rs) & $141243.6 \pm 190798.5$ \\
\hline Categorization of income ( $\%$ farmers) & \\
\hline $10,000-96,058$ & 61 \\
\hline $96,058-39,0252$ & 28 \\
\hline $390252-1000000$ & 11 \\
\hline Occupation status (\% farmers) & \\
\hline Full time farming & 40 \\
\hline Farming + Trading & 6 \\
\hline Farming + Govt. services & 48 \\
\hline Farming + other & 6 \\
\hline
\end{tabular}

Table.2 Social participation

\begin{tabular}{|l|l|}
\hline Particulars & Total $(\mathbf{n = 7 9})$ \\
\hline Village Panchayat & 10 \\
\hline Co-operatives & 0 \\
\hline Farmer's club & 0 \\
\hline Any other & 1 \\
\hline
\end{tabular}




\section{Table.3 Land holding}

\begin{tabular}{|c|c|}
\hline Parameter & Total $(n=79)$ \\
\hline Average landholding (ha) & $0.76 \pm 1.22$ \\
\hline Average irrigated area (ha) & $0.74 \pm 1.22$ \\
\hline Average unirrigated area (ha) & $0.01 \pm 0.11$ \\
\hline Categorization of farm size (\% farmers) & \\
\hline Marginal (<1ha) & 76 \\
\hline i) Small (1-2ha) & 16 \\
\hline ii) Semi medium (2-4ha) & 4 \\
\hline Medium (4-10ha) & 4 \\
\hline iv) Large (>10ha) & 0 \\
\hline Farmers with fragmented land holding (\% farmers) & 99 \\
\hline Average number of fragments & $4.4 \pm 3.3$ \\
\hline
\end{tabular}

Table.4

\begin{tabular}{l|c}
\multicolumn{1}{c|}{ Parameter** } & Total $(\mathbf{n}=79)$ \\
\hline Type of fertilizer used & 0 \\
Organic & 47 \\
Inorganic & 53 \\
Organic + Inorganic & \\
\hline Kind of fertilizer used & 0 \\
Liquid & 100 \\
Granulated & 1 \\
Powder & 2 \\
Tablets & 0 \\
Sustained Release & 1 \\
other & \\
Application of fertilizer & 91 \\
Self & 3 \\
Labour & 6 \\
Both &
\end{tabular}

Figures are percentages $*$ Multiple responses

Table.5 Prefer to purchase fertilizer on the basis of quantity

\begin{tabular}{|c|c|}
\hline & Total $(n=79)$ \\
\hline \multicolumn{2}{|l|}{ Urea $(n=79)$} \\
\hline Loose & 51 \\
\hline$<10 \mathrm{Kg}$ & 0 \\
\hline $25 \mathrm{Kg}$ & 3 \\
\hline $50 \mathrm{Kg}$ & 46 \\
\hline \multicolumn{2}{|l|}{ DAP $(n=78)$} \\
\hline Loose & 50 \\
\hline$<10 \mathrm{Kg}$ & 0 \\
\hline $25 \mathrm{Kg}$ & 4 \\
\hline $50 \mathrm{Kg}$ & 46 \\
\hline \multicolumn{2}{|l|}{ MOP $(n=6)$} \\
\hline Loose & 83 \\
\hline$<10 \mathrm{Kg}$ & 0 \\
\hline $25 \mathrm{Kg}$ & 0 \\
\hline $50 \mathrm{Kg}$ & 17 \\
\hline
\end{tabular}

Figures are percentages, multiple responses 
Table.6 Rating of different factors in purchasing fertilizer (\%farmers)

\begin{tabular}{|l|c|c|c|}
\hline \multicolumn{1}{|c|}{ Factors } & Not important & Neutral & Important \\
\hline Price & 54 & 34 & 12 \\
\hline Brand & 85 & 2 & 13 \\
\hline A vailability & 29 & 10 & 61 \\
\hline Nutrient compositions & 99 & 0 & 1 \\
\hline
\end{tabular}

Figures are percentages, multiple responses

Table.7 Extension contact

\begin{tabular}{|l|l|l|}
\hline Krishi Vigyan Kendra & A wareness $(\mathbf{n = 7 9})$ & Seek advice $(\mathbf{n = 7 9})$ \\
\hline Department of agriculture & 8 & 4 \\
\hline Agricultural university & 9 & 80 \\
\hline Input dealer & 85 & 5 \\
\hline Neighbours & 95 & 84 \\
\hline T.V. shows & 67 & 94 \\
\hline Print media & 21 & 65 \\
\hline Internet & 5 & 21 \\
\hline Kisan Call Centre & 9 & 5 \\
\hline
\end{tabular}

Figures are percentages, multiple responses

Table.8 Crop cultivation

\begin{tabular}{|l|c|c|c|c|c|}
\multirow{2}{*}{ Crop } & $\begin{array}{c}\text { Average } \\
\text { area (ha) }\end{array}$ & \multicolumn{2}{|c|}{ Average fertilizer applied (kg/ha) } & Organic (kg/ha) \\
\hline Rice & $0.76 \pm 1.23$ & $117.26 \pm 60.46$ & $123.34 \pm 68.21$ & $35.94 \pm 19.12$ & $652.88 \pm 361.96$ \\
\hline Wheat & $0.76 \pm 1.24$ & $113.98 \pm 61.99$ & $123.56 \pm 65.57$ & $17.67 \pm 19.39$ & $665.77 \pm 542.61$ \\
\hline
\end{tabular}

Table.9 Correlation coefficient of variables

\begin{tabular}{|l|l|l|l|}
\hline S. No. & Variables & Education Index & Land holding \\
\hline 1 & Age & $-0.233(0.039)^{*}$ & $-0.10(0.934)$ \\
\hline 2 & Occupation & $0.249(0.027)^{*}$ & $-0.024(0.832)$ \\
\hline 3 & Preference of purchase of Urea & $0.169(0.137)$ & $0.446(0.001)^{*}$ \\
\hline 4 & Preference of purchase of DAP & $0.155(0.176)$ & $0.449(0.001)^{*}$ \\
\hline 5 & Brand & $0.352(0.001)^{*}$ & $0.035(0.758)$ \\
\hline 6 & Income & $0.407(0.001)^{*}$ & $0.228(0.045)^{*}$ \\
\hline
\end{tabular}

Figures in parentheses are p- value

*Significant at 5 percent level of probability

With regards to rating of different factors in purchasing fertilizer, Table 6 revealed that 61 percent of the respondents gave importance to availability of the fertilizer. While $13 \%, 12 \%$ 
and $1 \%$ of the respondents gave importance to brand, price and nutrient compositions respectively.

With regard to extension contacts of the respondent farmers, 94 percent of the respondents seek advice from neighbours. $84 \%, 80 \%, 65 \%, 21 \%$ and $4 \%$ seek advice from input dealer, department of agriculture, T.V. shows, print media and Krishi Vigyan Kendra respectively. An equal percent (5\%) of the respondents seek advice from agricultural university, internet and Kisan Call Centre (Table 7).

The average area under rice crop was 0.76 hectares. Fertilizers being input for rice crop, applied at the rate of $117.26 \mathrm{~kg} /$ ha urea, $123.23 \mathrm{~kg} / \mathrm{ha}$ DAP, $35.94 \mathrm{~kg} / \mathrm{ha} \mathrm{MOP}$ and $652.88 \mathrm{~kg} / \mathrm{ha}$ FYM. While in case of wheat, the average area under cultivation was 0.76 hectare, fertilizers applied at the rates of $113.98 \mathrm{~kg} / \mathrm{ha}$ urea, $123.56 \mathrm{~kg} / \mathrm{ha}$ DAP, 17.67 $\mathrm{kg} / \mathrm{ha}$ MOP and $665.77 \mathrm{~kg} / \mathrm{ha}$ FYM (Table 8) which was very high against recommended dose and also the ratio of urea, DAP and MOP i.e.; 4:2:1 was not maintained (POP, 2016).

There was a significant negative correlation between age of the farmer and the educational index of family members of the farmers, it means young farmers had more educated family members than family members of old farmers. The correlation analysis showed that there was positive relationship between education index and occupation of the head of the family member, it means more the educated the members more they were doing good jobs. The correlation analyses also revealed that farmers having more land holding would prefer to buy urea in bulk quantity. Same is the case for DAP also (Table 9). From the matrix it was revealed that farmers who are more educated gave preference to brand while purchasing the fertilizers. From the table it was revealed that farmers having more landholding having more income.

From the analysis, it can be concluded that farmers were irrational in both usage and purchase of fertilizers. The quantity of fertilizer applied per hectare dependent on the type of crops grown and almost all the farmers apply more dosage of fertilizer than recommended. The NPK ratio applied was not in accordance as compared to the recommended. While estimating the preference for purchase, the farmers opined that easy availability, brand and price irrespective of nutrient composition of fertilizers. It is therefore, imperative that farmers need to be trained to use fertilizers in the right proposition and timely information should be given about different forms and kinds of fertilizers that are available.

\section{References}

Ali, Jabir. 2011. Adoption of Mass Media Information for Decision-Making among Vegetable Growers in Uttar Pradesh. Indian Journal of Agricultural Economic, 66(2): 241-254.

GOI. 2010. Agricultural Statistics at a Glance 2010 and earlier issues, Directorate of Economics and Statistics, Department of Agriculture and Cooperation, Ministry of Agriculture, Govt. of India, New Delhi.

Kapoor, Nimish. 2011. Role of Mass Media in Promotion of Environmental Awareness along with Skill Development among the Rural People of Shringverpur, Allahabad District, India. International Conference on Chemical, Biology and Environment Science (ICCEBS'2011) Bangkok.

Kulkarni, Vishwanath. "Agriculture: On the cusp of self-sufficiency." The Hindu. 14 August 2017. Web. 5 Feb. 2018. 
POP, 2016. Package of Practice of Rabi crops. SKUAST- Jammu. Available at http://skuast.org/site/Templates\%20HT ML/extension/pop-rabi.pdf

Sharma, Vijay Paul and Thaker, Hrima. 2011. Demand for Fertilizer in India:
Determinants and Outlook for 2020, W.P. No. 2011-04-01, Indian Institute of Management Ahmedabad-380 015 India.

\section{How to cite this article:}

Yudhishther Singh Bagal, L.K. Sharma, Gunjan Preet Kaur, Arjun Singh and Priya Gupta. 2018. Trends and Patterns in Fertilizer Consumption: A Case Study. Int.J.Curr.Microbiol.App.Sci. 7(04): 480-487. doi: https://doi.org/10.20546/ijcmas.2018.704.056 